\title{
TIMING AND PRESENTATION EFFECTS IN SEQUENTIAL AUCTIONS
}

\section{Ola Andersson}

Uppsala University and Research Institute of Industrial Economics, Sweden ola.andersson@nek. uu.se

Tommy Andersson

Lund University, Sweden

tommy . andersson@nek. lu.se

\begin{abstract}
This paper investigates two hitherto unexplored dimensions inherent in online sequential auctions, namely, how the time elapsed between the end of an auction and the end of the next one and the order of presentation on the website affect prices. Using a state-of-the-art-dataset on train-ticket auctions with a particular institutional design feature that enables a causal interpretation of these dimensions, it is demonstrated that both dimensions have a significant impact on price formation in sequential auctions.
\end{abstract}

Keywords: Sequential auctions, presentation order, timing afternoon effect. JEL Classification Numbers: D02, D44.

\section{INTRODUCTION}

Q equential auction formats are commonly adopted when selling multiple $\curvearrowright$ units of a good within a predetermined time frame. Examples include the selling of flowers, highway paving contracts, school milk contracts, timber, and wine Jofre-Bonet \& Pesendorfer (2003). There are several reasons for the popularity of the format. Firstly, it requires relatively little information

The authors gratefully acknowledge financial support from the Ragnar Söderberg Foundation (research grant E8/13).

Copyright (c) Ola Andersson, Tommy Andersson / 2(1), 2017, 39-55. 
exchange among the buyers and the auctioneer. Secondly, it easily accommodates scenarios in which buyers enter and leave the market. Thirdly, it allows the auctioneer to allocate items incrementally (Bae et al., 2009). A formal theoretical analysis of the auction format is, however, not straightforward. Consequently, much of the attention in the literature has been restricted to the case when items are identical and buyers have unit-demand. In this setting, Milgrom \& Weber (1982) show that expected prices in a sequence of second-price auctions (Vickrey, 1961) with identical items should be equal. The empirical literature has, however, refuted this prediction by showing that prices are decreasing in rank order, i.e., the order in which the auctions in the sequence are terminated (see, e.g., Ashenfelter, 1989; McAfee \& Vincent, 1993; van den Berg et al., 2001). ${ }^{1}$ This decreasing price anomaly has been coined "the afternoon effect" because auctions later in a sequence typically took place in the afternoon whereas early auctions typically took place in the morning. Evidence of increasing price sequences has been observed by Raviv (2006) and Gandal (1997). ${ }^{2}$ Hence, the phenomenon does not seem universal.

Studying the rank order effect on prices of identical items in sequential auctions is natural as this is the most easily observed variation in happenstance auction data; see e.g., van den Berg et al. (2001). This paper takes one step further and utilizes a state-of-the-art data set on online train-ticket auctions in Sweden to investigate two hitherto unexplored dimensions inherent in sequential auctions. The first concerns the order in which the auctioned items are presented on the website and the second concerns the time elapsed between auction terminations. Using a particular institutional design, random variation in these dimensions are exploited to make causal inference of their effect on prices. In sum, it is found that both these dimensions have a significant impact on prices.

It has previously been demonstrated that the time elapsed between auctions in a sequence may affect prices. For example, Andersson et al. (2012) find that when auction ends are identical, considerable price heterogeneity is observed

1 Ashenfelter (1989), Beggs \& Graddy (1997) and Hong et al. (2015) found that this observation also holds for heterogeneous items. Decreasing price sequences have also been found in auction formats where auction winners have the option to buy items in subsequent auctions (Février et al., 2007) or when they have the option to place the first bid in subsequent auctions (Lambson \& Thurston, 2006).

2 Ginsburgh (1998) and Deltas \& Kosmopoulou (2004) find both increasing and decreasing price sequences. They argue that these observations could be due to non-strategic absent bidders who submit their bids previous to the auction start. 
between auctions, and Zeithammer (2006) shows that bids are lower when similar items are being auctioned off in the near future. On the other hand, Anwar et al. (2006) observe that bidders are less likely to bid on identical items if their respective auction end times are far apart. Hence, the time elapsed between auctions may be an important factor for price formation in sequential auctions, which calls for further studies. In sequential auctions the time elapsed between the auctions is, typically, held constant, but the difference between auction formats could be considerable ranging from just a few minutes up to several days apart. Typically, however, the exact timing of auctions has seldom been recorded in previous studies which makes it hard to study the timing effect. To the contrary, the data investigated in this paper include exact recordings of auction ends and, moreover, exhibit a random variation between auction ends (exact details to be described below). This gives a unique possibility to study the timing effect.

Regarding the presentation order, note that choices in Milgrom \& Weber (1982) are modeled from the perspective of a set of items being auctioned off. Yet, bidders, in real life, typically face lists of items being auctioned off and the presentation order on the list may influence their decisions. This may create a "primacy effect", i.e., items with a high position on a list are more prominent than items with a low position. A reversed "recency effect" means that items placed low are more prominent than items placed high(see, e.g., Rubinstein \& Salant, 2006, for a discussion). ${ }^{3}$ Deltas \& Kosmopoulou (2004) study sequential auctions of rare books. The books are described in an auction catalogue and placed in alphabetical order so, although being heterogenous items, they are seemingly randomly placed. They find an overall increasing price pattern and, furthermore, that books described further down in the catalogue receive fewer bids from e-mail bidders. ${ }^{4}$ This suggests a primacy effect. However, in their data, the rank order is identical to the presentation order and, as a consequence, their result may also be due to a rank-order effect effect or a combination of the two. This paper seeks to separate the effect of rank order to that of the timing and presentation order.

3 In the literature on sponsored search (e.g., Agarwal et al., 2011) and position auctions (e.g., Edelman et al., 2007), evidence of a primacy effect, from the perspective of the seller, is found. Recently, a primacy effect has been found in terms of downloads of new working papers from the NBER website (Feenberg et al., 2015).

4 Bids could be submitted by e-mail before the auction start or placed "on the floor" during the auction. 
This paper uses data from more than 42,000 online train ticket auctions grouped into 7,200 sequential auctions. ${ }^{5}$ From the perspective of the bidders, each ticket in a sequential auction is completely homogenous in terms of its characteristics (route, class, and time of departure), its seller (the state-owned train company), its reserve price (1 SEK), and its transaction cost (literally zero as tickets are delivered by an SMS text message to the buyer). This feature is quite rare in the literature on sequential auctions. In fact, the only variables that vary within an group of sequential auctions are the termination time of the auctions, i.e., their rank order (the first auction has rank order one, the second two, and so on), and the order in which they are presented on the auction website, i.e., presentation order (the auction presented at the very top of the website has presentation order one, and so forth). In every sequential auction sequence, each ticket is assigned an auction number which determines the presentation order on the auction website. Moreover, each ticket auction in a sequence is set to end within a given hour. However, the exact ending minute of each auction is determined by a random draw. Consequently, the rank order is different from the presentation order and the time elapsed between two consecutive auction ends is random. These novel design features are used to identify and separate the effect of rank order to that of the timing and presentation order (i.e., it is a natural field experiment in the terminology of Harrison \& List, 2004). To the best of our knowledge, this article is the first to make this separation and causally estimate how these dimensions affect prices in sequential auctions. ${ }^{6}$

The analysis reveals that the presentation order has a non-linear impact on prices, so that it pays off to be first or last in the list. Moreover, if ending times of two consecutive auctions are close, this has a negative impact on prices in both auctions. However, the relationship shows substantial non-linearities so being placed far apart also depresses prices. From an auction-designer's perspective, these insights are important when trying to curb the afternoon effect to secure higher revenues. Finally, in line with the bulk of the previous empirical literature, a negative rank order effect (i.e., an afternoon effect) is found. We also note that the rank order effect is essentially unchanged when controlling for presentation order and timing and, hence, a substantial part of the anomaly persists indicating that further research is needed to fully

5 See Bajari \& Hortacsu (2004) for an excellent summary of internet-auction studies.

6 However, using field experiments to study behavior in auctions is not new. See, for example, Lucking-Reiley (1999), List \& Lucking-Reiley (2000), or Grether et al. (2015). 
understand the afternoon effect.

The remaining part of the paper is outlined as follows. Section 2 describes the sequential online auction format. The data are described and analyzed in Sections 3 and 4, respectively. Section 5 concludes that paper. The Appendix contains some additional estimations.

\section{THE SEQUENTIAL TRAIN TICKET AUCTION}

Statens Järnvägar (SJ, henceforth) is a publicly owned company that mainly runs passenger trains in Sweden. In 2007, they began to auction train tickets on the eBay-owned website Tradera which is the leading auction site in Sweden. ${ }^{7}$ This section describes the sequential auction mechanism that was adopted by SJ on November 15, 2010 and for the duration of the collected data.

Before introducing the notion of a sequence of auctions, it is noted that each train ticket is auctioned off in a separate auction. More specifically, each ticket is displayed on the website of Tradera exactly at 9pm at date $t$, and the following information is available for potential bidders; (i) date of departure, (ii) the "time block" when the train departures (05:00am-09:59am, 10:00am-02:59pm, or 03:00pm-08:59pm), (iii) departure station, and (iv) final destination. The reserve price of a ticket is always set to 1 SEK (approximately 0.11 USD). Bidders place bids by entering a maximum amount that they are willing to pay for the ticket. An automatic bidder (a proxy bidding agent) places bids on behalf of the agent using an automatic bid increment amount which depends on the current standing bid. The proxy bidder will only bid as much as necessary to make sure that the bidder remains the highest bidder up to the bidder's maximum amount (note that a bidder's maximum willingness to pay is kept confidential until it is exceeded by another bidder). The winner is the bidder with the highest bid when the auction ends, and the winner pays one bid increment above the highest losing bid. In this sense, each train ticket auction resembles a second-price auction (Vickrey, 1961) even if it can be argued that it is a hybrid between a second-price and a first-price auction due to the role of the bid increment (see Hickman, 2010). ${ }^{8}$ Upon winning an auction,

7 Because the train ticket auctions are organized by SJ, the tickets are not resales. See Yoshimoto \& Nakabayashi (2016) for a recent paper on resales of train tickets in Japan.

8 It has also been noted by Hickman (2010), Hickman et al. (2011) and Tukiainen (2013) that bid shading may be optimal when the price is set to one increment above highest loosing bid. However, we conjecture that this issue is orthogonal to what we study here as the bid shading 
the winning bidder is directly asked to fill in his name and cell phone number, and the ticket is subsequently sent as a personal ticket by an SMS text message. This final feature makes it hard to resell a previously-won ticket, if the name and phone number of that buyer were not available to the auction winner at the time of winning the auction.

Two tickets are considered to be identical if conditions (i)-(iv) from the above are identical as there is no way of distinguishing between the tickets. A set of auctions with identical tickets is called a sequential auctions (SA, henceforth). Each ticket auction in a SA is given an auction number which determines the presentation order on the website, i.e., the auction with the lowest number is displayed highest up on the website and has presentation order 1, the auction that is displayed second highest up has presentation order 2 , and so on.

The rank order of an auction within a given SA is defined as the order in which the auction is terminated, i.e., the auction that terminates first in a given SA has rank order 1, the auction that terminates second in the same SA has rank order 2, and so forth. Each auction in a SA ends on date $t+2$ between $9 \mathrm{pm}$ and $10 \mathrm{pm}$, but more importantly, the exact ending minute of the auction is determined by a random draw from a uniform distribution on [0,59] that is made before the auction is announced on the website. As a consequence, the rank order and the presentation order for a ticket in a given SA may differ, and, moreover, the time span between two consecutive auctions in a SA is random. Hence, this allows us to disentangle the effect of timing and presentation order from that of the rank order effect. Yet, we note that the presentation order is based on the default ordering on the website and a bidder may alter this ordering by using different filters (e.g., auction ending time) which may put a downward bias on how our definition of presentation order affects prices.

\section{DATA DESCRIPTION}

The data set consists of all train tickets sold by SJ on Tradera during the period 2010-11-15 to 2011-06-14. In total, 42,007 tickets were sold for 42 different departure-destination routes during this period. These tickets can be partitioned into 7,202 sequential auctions with a total of more than 15,000 participating bidders.

will be constant within an auction sequence.

Journal of Mechanism and Institution Design 2(1), 2017 
Table 1 summarizes the main characteristics of interest by route. As can be seen from Table 1, some routes, usually from and/or to small communities, contain very few observations. These may be routes where auctions failed to generate enough bidding or "trial routes" that were discontinued. In addition, some particular routes, typically only the most popular ones (e.g., Göteborg C - Stockholm C), contain a few sequential auctions with very long sequences. In the empirical analysis, we exclude the 10 routes with fewer than 100 tickets, and all sequential auctions containing more than 15 tickets. We also exclude auctions with only one bidder. Given these restrictions, the reduced dataset still contains 5,999 sequential auctions with a varying number of bidders and tickets.

Table 1: Summary statistics for the considered departure-destination routes.

\begin{tabular}{|c|c|c|c|c|c|c|c|c|}
\hline Departure - Destination & \#A & \#B/A (mean) & \#B/A (sd) & \#SA & Price (mean) & Price (sd) & Min price & Max price \\
\hline Arvika stn - Stockholm C & 13 & 2.2 & 1.3 & 5 & 51.8 & 114.2 & 1.0 & 330.0 \\
\hline Duved stn - Stockholm C & 166 & 2.5 & 1.2 & 41 & 72.4 & 87.9 & 1.0 & 350.0 \\
\hline Falun C - Stockholm C & 2393 & 3.5 & 1.5 & 433 & 70.5 & 51.9 & 1.0 & 263.0 \\
\hline Göteborg C - Kalmar C & 5 & 1.2 & 0.4 & 5 & 1.2 & 0.4 & 1.0 & 2.0 \\
\hline Göteborg C - Koebenhavn H & 470 & 4.0 & 1.8 & 119 & 63.2 & 51.4 & 1.0 & 235.0 \\
\hline Göteborg C - Malmö C & 885 & 3.6 & 1.7 & 184 & 68.5 & 55.1 & 1.0 & 265.0 \\
\hline Göteborg C - Oesterport & 559 & 3.8 & 1.8 & 103 & 56.8 & 50.4 & 1.0 & 280.0 \\
\hline Göteborg C - Stockholm C & 5385 & 5.5 & 2.6 & 480 & 188.2 & 141.2 & 1.0 & 900.0 \\
\hline Göteborg C - Sundsvall C & 2 & 1.0 & 0.0 & 1 & 1.0 & 0.0 & 1.0 & 1.0 \\
\hline Halmstad C - Stockholm C & 111 & 5.0 & 2.4 & 27 & 213.0 & 147.2 & 1.0 & 500.0 \\
\hline Hudiksvall stn - Stockholm C & 3 & 1.7 & 1.2 & 1 & 2.3 & 2.3 & 1.0 & 5.0 \\
\hline Kalmar C - Göteborg C & 2 & 1.0 & 0.0 & 2 & 1.0 & 0.0 & 1.0 & 1.0 \\
\hline Karlstad C - Stockholm C & 2548 & 3.3 & 1.7 & 564 & 81.7 & 82.9 & 1.0 & 460.0 \\
\hline Kiruna C - Luleå C & 416 & 2.2 & 1.1 & 177 & 50.0 & 61.5 & 1.0 & 245.0 \\
\hline Koebenhavn H - Göteborg C & 281 & 4.1 & 1.6 & 70 & 75.1 & 51.0 & 1.0 & 250.0 \\
\hline Koebenhavn $\mathrm{H}$ - Stockholm C & 147 & 5.9 & 2.2 & 44 & 193.9 & 117.0 & 1.0 & 560.0 \\
\hline Luleå C - Kiruna C & 400 & 2.3 & 1.2 & 169 & 60.3 & 67.7 & 1.0 & 280.0 \\
\hline Luleå C - Narvik & 379 & 2.2 & 1.1 & 158 & 51.5 & 62.8 & 1.0 & 389.0 \\
\hline Malmö C - Göteborg C & 951 & 3.6 & 1.7 & 217 & 67.7 & 59.6 & 1.0 & 305.0 \\
\hline Malmö C - Stockholm C & 3219 & 5.6 & 2.3 & 437 & 205.9 & 124.9 & 1.0 & 710.0 \\
\hline Mora stn - Stockholm C & 3 & 1.7 & 0.6 & 1 & 6.7 & 8.1 & 1.0 & 16.0 \\
\hline Narvik - Luleå C & 370 & 2.1 & 1.2 & 161 & 45.8 & 59.6 & 1.0 & 327.0 \\
\hline Odense - Stockholm C & 23 & 5.3 & 2.3 & 5 & 144.9 & 114.6 & 7.0 & 370.0 \\
\hline Oesterport - Göteborg C & 925 & 3.5 & 1.7 & 152 & 54.1 & 48.1 & 1.0 & 231.0 \\
\hline Oesterport - Stockholm C & 219 & 6.4 & 2.3 & 53 & 264.5 & 141.8 & 4.0 & 630.0 \\
\hline Stockholm C - Borlänge C & 392 & 3.0 & 1.5 & 105 & 50.8 & 47.3 & 1.0 & 260.0 \\
\hline Stockholm C - Duved stn & 178 & 2.8 & 2.0 & 50 & 85.0 & 121.9 & 1.0 & 491.0 \\
\hline Stockholm C - Falun C & 2098 & 3.3 & 1.7 & 447 & 63.1 & 56.5 & 1.0 & 295.0 \\
\hline Stockholm C - Göteborg C & 5411 & 5.0 & 2.8 & 469 & 169.1 & 157.2 & 1.0 & 1075.0 \\
\hline Stockholm C - Halmstad C & 45 & 3.3 & 2.5 & 14 & 122.0 & 153.1 & 1.0 & 598.0 \\
\hline Stockholm C - Karlstad C & 2582 & 3.1 & 1.6 & 487 & 70.6 & 79.2 & 1.0 & 510.0 \\
\hline Stockholm C - Koebenhavn H & I 224 & 5.7 & 2.3 & 73 & 240.6 & 130.8 & 1.0 & 667.0 \\
\hline Stockholm C - Malmö C & 1931 & 5.8 & 2.2 & 347 & 234.7 & 136.8 & 1.0 & 1225.0 \\
\hline Stockholm C - Odense & 4 & 4.3 & 0.5 & 1 & 169.8 & 65.6 & 105.0 & 261.0 \\
\hline Stockholm C - Oesterport & 786 & 4.9 & 2.3 & 166 & 193.9 & 147.8 & 1.0 & 1125.0 \\
\hline Stockholm C - Sundsvall C & 3176 & 3.8 & 1.8 & 451 & 104.5 & 96.5 & 1.0 & 550.0 \\
\hline Stockholm C - Åre stn & 508 & 3.3 & 1.8 & 106 & 117.4 & 121.1 & 1.0 & 550.0 \\
\hline Stockholm C - Östersund C & 597 & 3.5 & 1.4 & 158 & 129.6 & 120.6 & 1.0 & 760.0 \\
\hline Sundsvall C - Stockholm C & 3095 & 4.2 & 1.9 & 449 & 119.2 & 95.8 & 1.0 & 600.0 \\
\hline Ånge stn - Stockholm C & 1 & 1.0 & - & 1 & 1.0 & - & 1.0 & 1.0 \\
\hline Åre stn - Stockholm C & 379 & 3.7 & 2.0 & 84 & 126.0 & 115.3 & 1.0 & 580.0 \\
\hline Östersund C - Stockholm C & 725 & 4.0 & 1.9 & 185 & 150.7 & 132.4 & 1.0 & 810.0 \\
\hline Total & 42007 & 4.3 & 2.3 & 7202 & 129.6 & 125.8 & 1.0 & 1225.0 \\
\hline
\end{tabular}

Notes: A set of auctions with identical tickets is called a sequential auctions or SA for short. $\# \mathrm{~A}=$ number of auctions, $\# \mathrm{~B} / \mathrm{A}=$ number of bidders per auction, \#SA = number of $\mathrm{SA}$, and $\mathrm{sd}=$ standard deviation. 
Table 2: The effects of rank order, presentation order, and timing on prices.

\begin{tabular}{|c|c|c|c|}
\hline Dependent variable: Price & Model (1) & Model (2) & Model (3) \\
\hline Rank order & $\begin{array}{r}-3.863 * * * \\
(0.850)\end{array}$ & $\begin{array}{r}-3.837 * * * \\
(0.850)\end{array}$ & $\begin{array}{r}-4.133 * * * \\
(0.840)\end{array}$ \\
\hline Rank order ${ }^{2}$ & $\begin{array}{r}0.140 * \\
(0.0739)\end{array}$ & $\begin{array}{r}0.138 * \\
(0.0740)\end{array}$ & $\begin{array}{r}0.159 * * \\
(0.0732)\end{array}$ \\
\hline Presentation order & & $\begin{array}{r}-1.260 * * * \\
(0.461)\end{array}$ & $\begin{array}{r}-0.988 * * \\
(0.460)\end{array}$ \\
\hline Presentation order ${ }^{2}$ & & $\begin{array}{r}0.0815 * * \\
(0.0383)\end{array}$ & $\begin{array}{c}0.0644^{*} \\
(0.0380)\end{array}$ \\
\hline Minutes to previous & & & $\begin{array}{r}2.802 * * * \\
(0.224)\end{array}$ \\
\hline Minutes to previous $^{2}$ & & & $\begin{array}{r}-0.0964 * * * \\
(0.0108)\end{array}$ \\
\hline Minutes to next & & & $\begin{array}{r}1.615 * * * \\
(0.215)\end{array}$ \\
\hline Minutes to next ${ }^{2}$ & & & $\begin{array}{r}-0.0568 * * * \\
(0.0104)\end{array}$ \\
\hline Constant & $\begin{array}{r}154.0 * * * \\
(2.079)\end{array}$ & $\begin{array}{r}157.2^{* * * *} \\
(2.329)\end{array}$ & $\begin{array}{r}141.8 * * * \\
(2.513)\end{array}$ \\
\hline Observations & 18,718 & 18,718 & 18,718 \\
\hline R-squared & 0.011 & 0.012 & 0.031 \\
\hline Number of SA & 5,036 & 5,036 & 5,036 \\
\hline
\end{tabular}

Notes: Sample restricted by excluding first and last auction to make samples in the three models identical. Robust standard errors in parentheses. $* * * p<0.01$, ** $p<0.05, * p<0.1$.

\section{ANALYSIS}

A linear fixed effects model where each SA is treated as an unbalanced panel is estimated in the sample. The chosen specifications are quite flexible as we allow for quadratic terms in all variables of interest. Table 2 shows the main estimation results. Model (1) is the baseline model in which no controls for presentation order and timing are included. Model (2) includes a control for presentation order, and Model (3) also includes controls for timing by measuring the distance, in minutes, to the previous ("Minutes to previous") and next ("Minutes to next") auction in a SA. ${ }^{9}$ Model (1) confirms the existence

9 Note that the sample is kept constant in Models (1)-(3), i.e., since the first and last auctions in a SA must be excluded in Model (3), to include the timing variables, these auctions are also absent in Models (1) and (2). Table 4 in the Appendix reports the results where Models 
of an afternoon effect when not controlling for timing and presentation order. This is in line with previous findings in the literature, e.g., Ashenfelter (1989), McAfee \& Vincent (1993), and van den Berg et al. (2001).

The left panel in Figure 1 shows the estimated average marginal effect of rank order on prices for Model (3) in Table 2, and it illustrates that the negative price trend continues to hold also for high rank orders even though the effect is diminishing as the rank order increases. The right panel in Figure 1 shows the estimated marginal effect of presentation order on prices for Model (3) in Table 2. From the figure, it can be seen that the optimal placement, from the perspective of the seller, is at the top of the website. This indicates a primacy effect and corroborates previous findings from sponsored search literature (see, e.g., Agarwal et al., 2011). However, in contrast to the literature on sponsored search, where the items are heterogenous and their position usually is determined by a position auction (see, e.g., Edelman et al., 2007; Varian, 2007), the train tickets in a given SA are completely homogenous. Note also that even though there is a negative effect associated with presentation order, the effective size is less than half the effect of the rank order of the auction. As noted earlier, this may be partly explained by bidders using filters to re-order the presentation of tickets.

The left panel (right panel) in Figure 2 shows the distribution in minutes to the next (previous) auction, and the right panel (left panel) in Figure 3 shows the estimated average effect of time from subsequent (previous) auction on prices for for Model (3) in Table 2. As can be seen in the figure, there is an upward sloping trend for small time differences. This trend can, at least partly, be explained by the results in Andersson et al. (2012) and the theoretical predictions in Zeithammer (2006). The former suggests that if auction ends are identical, bidders may have problems cross bidding, i.e., it may be difficult for bidders to coordinate bids between auctions with similar termination times. The latter, on the other hand, suggests that bidders are more likely to be forward looking when subsequent auctions are closer which makes bidders less willing to place high bids in the current auction.

In general, the timing effect shows an inverted U-shape to the previous (subsequent) auction. One potential explanation for this price hike is that the more time that has passed since the previous auction ended, the more

(1) and (2) include the first and last auction in a SA. The results are qualitatively similar but coefficients on rank order is smaller. The model is also estimated using the full sample in Table 5 in the Appendix. 

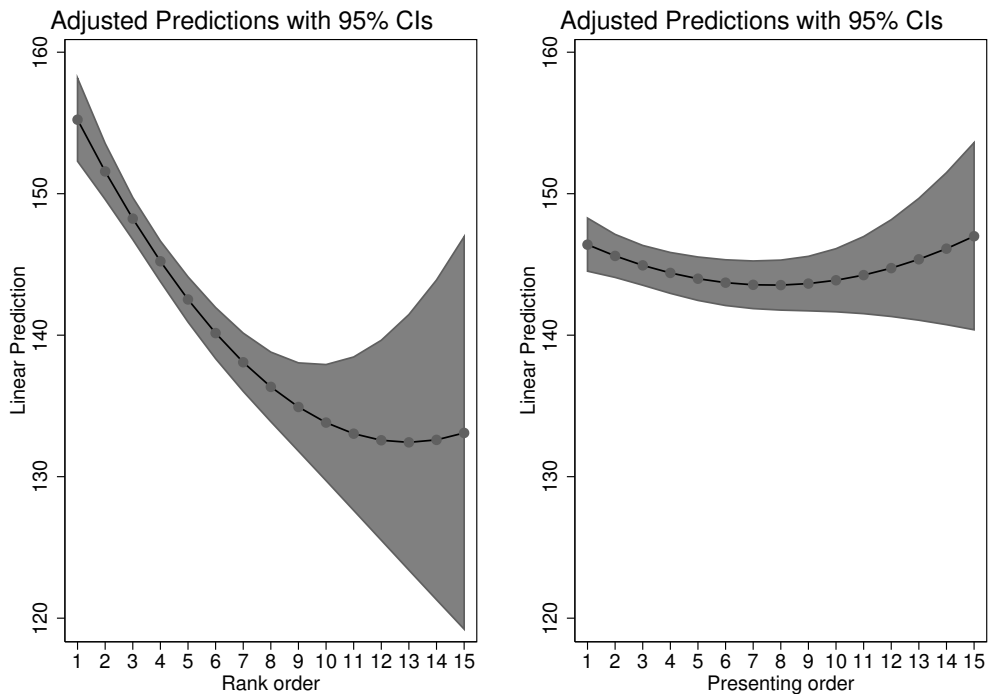

Figure 1: Marginal effect of rank order.
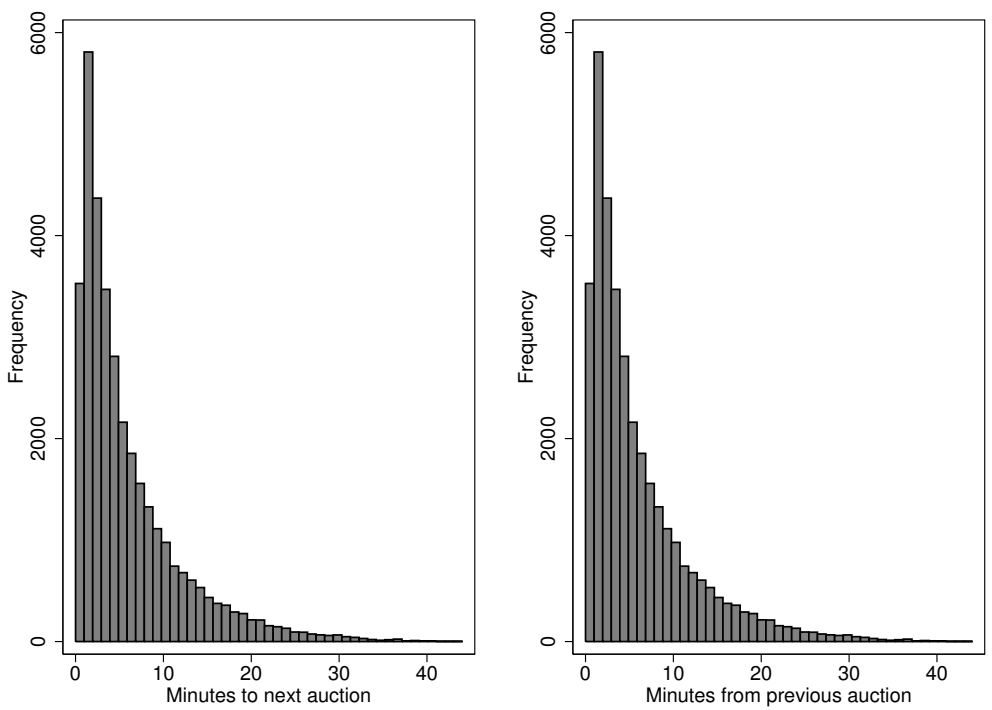

Figure 2: Minutes to previous and next auction. 
bidders have been able to enter and place bids in the current auction. The fact that timing seems to matter for the evolution of price sequences is interesting and we have not found any such result in the literature. According to the estimations, the optimal timing is to have auction ends approximately 15 minutes apart, which may counteract the rank order effect.
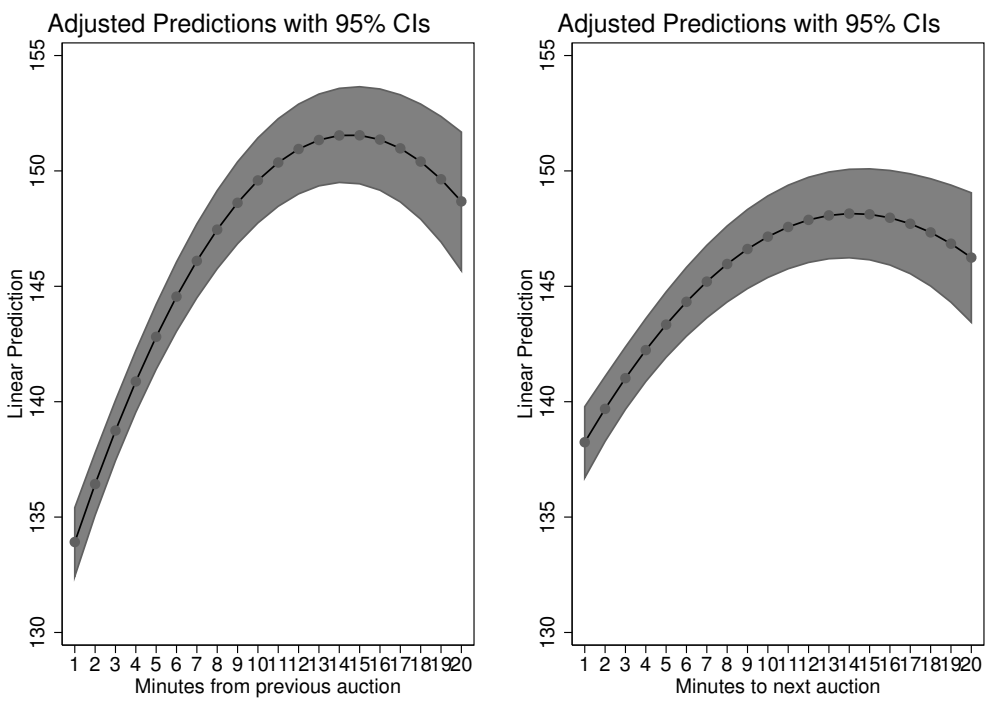

Figure 3: Marginal effect of timing.

\subsection{Unit-demand Bidders}

The previous analysis shows that both the time elapsed between auction ends and the presentation order are important for price formation in sequential auctions, but that they cannot fully explain the negative rank order effect (i.e., the afternoon effect). One possible explanation of the latter finding is that the analysis in Milgrom \& Weber (1982) explicitly considers unit-demand bidders. Unfortunately, as in many real-world applications and all empirical studies on sequential auctions, it is not possible to observe whether bidders have unit-demand or not. What is possible to observe in the current study, however, is the number of tickets within a specific SA that a particular bidder 
has won. ${ }^{10}$

Table 3: The effects of rank order, presentation order, and timing on prices (unit demand).

\begin{tabular}{lrrr}
\hline \hline Dependent variable: Price & Model (1) & Model (2) & Model (3) \\
\hline Rank order & $-1.551^{*}$ & $-1.529^{*}$ & $-4.720^{* * *}$ \\
& $(0.897)$ & $(0.893)$ & $(1.522)$ \\
Rank order & 2 & 0.161 & $0.270^{*}$ \\
& 0.162 & $(0.0991)$ & $(0.143)$ \\
Presentation order & $(0.0995)$ & $-1.590^{* *}$ & -1.020 \\
& & $(0.792)$ & $(0.993)$ \\
Presentation order & & 0.130 & 0.0825 \\
& & $(0.0833)$ & $(0.0988)$ \\
Minutes to previous & & & $3.151^{* * *}$ \\
& & & $(0.343)$ \\
Minutes to previous ${ }^{2}$ & & & $-0.104^{* * *}$ \\
& & & $(0.0148)$ \\
Minutes to next & & & $1.978^{* * *}$ \\
& & & $(0.360)$ \\
Minutes to next ${ }^{2}$ & & & $-0.0618^{* * *}$ \\
& & & $(0.0165)$ \\
Constant & $165.4^{* * *}$ & $168.5^{* * *}$ & $149.5^{* * *}$ \\
& $(1.676)$ & $(2.231)$ & $(4.559)$ \\
Observations & & & \\
R-squared & 14,035 & 14,035 & 7,463 \\
Number of SA & 0.001 & 0.001 & 0.031 \\
\hline
\end{tabular}

Notes: Sample restricted to SA's where each bidder won at most one ticket. Robust standard errors in parentheses. ${ }^{* * *} p<0.01,{ }^{* *} p<0.05,{ }^{*} p<0.1$.

In Table 3, the same set of regressions as in Table 4 are run but restricting the sample to situations where each bidder in the SA only won at most one auction. As can be seen from the table, the rank order effect is still negative but smaller and now only significant at the ten percent level for Models (1) and (2). Model (3) is more inline with its full-sample counterpart, displaying a sizable negative rank order effect. Results from the first two specifications

${ }^{10}$ In the investigated auction, it was possible to buy multiple train tickets. However, it should be noticed that each ticket was personal and a ticket holder may have had to show identification when validating the ticket with the conductor. It is, however, unknown to the authors whether this institution was strictly enforced or not. Another possibility to buy multiple tickets was to place bids using different accounts on the auction platform. 
suggest that multi-unit demand may partly help to explain the decreasing price anomaly. Yet, the third specification suggests not. What is special with this last specification, except for controlling for timing effects, is that it excludes the first and the last auction in a SA. If the price drop is most notable in the very first auction, then this may explain the effect but there is no way to tell if this is true or not given the limitations of the data. Finally, note that the coefficients on timing are intact to the sample restriction. The size of the effect of presentation order are similar albeit insignificant under the third specification, which may be explained by the smaller sample.

\section{CONCLUSIONS}

This paper has investigated how prices are affected by the time elapsed between auction ends and the presentation order on the website. It has been demonstrated that the presentation order on the auction website has a significant impact on prices. Yet, the effect follows a U-shape. Hence, it pays off to be one of the first or last auctions presented. When it comes to the effect on prices of the time elapsed between two consecutive auctions, it is found that having closeness in the time dimension has a negative impact on prices in both auctions. Consequently, the policy implication for the auction designer is that one should be careful in posting two auctions "too close" to each other as it may result in lower prices for both items. Moreover, by randomizing the presentation order, the primacy effect may be down-played, but as it is hard to inherently control this order, its effect on prices may be small.

Received theory predicts that prices in a sequence of auctions with identical items should be equal. Yet, even when controlling for presentation order, the timing of auctions, and by restricting the dataset to unit-demand bidders, it is found that average auction prices are declining in a sequence. This further strengthens the anomalous findings (i.e., the afternoon effect) in the existing empirical auction literature. Given this insight, it is logical to search for a theoretical explanation of this phenomenon that can be empirically tested. Unfortunately, none of the theoretical explanations that we are aware of (e.g., Ashenfelter, 1989; McAfee \& Vincent, 1993; von der Fehr, 1994; Mezzetti, 2011; Rosato, 2014) have predictions that can be tested empirically unless estimates of the risk preferences, loss aversion or participation costs are available. The problem of finding alternative theoretical explanations to the afternoon effect is left for future research. 


\section{APPENDIX: ADDITIONAL ESTIMATIONS}

Table 4 describes the re-estimation of the models in Table 2 but allowing the sample to vary over the three models. Table 5 replicates the estimation in Table 2 but using the full sample.

Table 4: The effects of rank order, presentation order, and timing on prices.

\begin{tabular}{lrrr}
\hline \hline Dependent variable: Price & Model (1) & Model (2) & Model (3) \\
\hline Rank order & $-2.788^{* * *}$ & $-2.767^{* * *}$ & $-4.133^{* * *}$ \\
& $(0.566)$ & $(0.567)$ & $(0.840)$ \\
Rank order $^{2}$ & $0.148^{* * *}$ & $0.148^{* * *}$ & $0.159^{* *}$ \\
Presentation order & $(0.0542)$ & $(0.0543)$ & $(0.0732)$ \\
& & $-0.966^{* *}$ & $-0.988^{* *}$ \\
Presentation order & & $(0.404)$ & $(0.460)$ \\
& & 0.0531 & $0.0644^{*}$ \\
Minutes to previous & & $(0.0347)$ & $(0.0380)$ \\
& & & $2.802^{* * *}$ \\
Minutes to previous & & & $(0.224)$ \\
Minutes to next & & & $-0.0964^{* * *}$ \\
Minutes to next & & & $(0.0108)$ \\
Constant & & & $1.615^{* * *}$ \\
& & & $(0.215)$ \\
Observations & & & $-0.0568^{* * *}$ \\
Number of SA & & & $(0.0104)$ \\
\hline \hline
\end{tabular}

Notes: Robust standard errors in parentheses. *** $p<0.01, * * p<0.05, * p<0.1$. 
Table 5: The effects of rank order, presentation order, and timing on prices. Full sample.

\begin{tabular}{|c|c|c|c|}
\hline Dependent variable: Price & Model (1) & Model (2) & Model (3) \\
\hline Rank order & $\begin{array}{r}-3.235 * * * \\
(0.237)\end{array}$ & $\begin{array}{r}-3.209 * * * \\
(0.237)\end{array}$ & $\begin{array}{r}-4.094 * * * \\
(0.258)\end{array}$ \\
\hline Rank order ${ }^{2}$ & $\begin{array}{r}0.0335 * * * \\
(0.00554)\end{array}$ & $\begin{array}{r}0.0329 * * * \\
(0.00556)\end{array}$ & $\begin{array}{r}0.0473 * * * \\
(0.00679)\end{array}$ \\
\hline Presentation order & & $\begin{array}{r}-0.527 * * * \\
(0.117)\end{array}$ & $\begin{array}{r}-0.318 * * * \\
(0.121)\end{array}$ \\
\hline Presentation order ${ }^{2}$ & & $\begin{array}{r}0.00204 \\
(0.00313)\end{array}$ & $\begin{array}{r}-0.00126 \\
(0.00315)\end{array}$ \\
\hline Minutes to previous & & & $\begin{array}{r}3.173 * * * \\
(0.190)\end{array}$ \\
\hline Minutes to previous $^{2}$ & & & $\begin{array}{r}-0.113 * * * \\
(0.00933)\end{array}$ \\
\hline Minutes to next & & & $\begin{array}{r}1.729 * * * \\
(0.182)\end{array}$ \\
\hline Minutes to next ${ }^{2}$ & & & $\begin{array}{r}-0.0620 * * * \\
(0.00884)\end{array}$ \\
\hline Constant & $\begin{array}{r}144.4 * * * \\
(1.084)\end{array}$ & $\begin{array}{r}146.9 * * * \\
(1.186)\end{array}$ & $\begin{array}{r}132.9 * * * \\
(1.620)\end{array}$ \\
\hline Observations & 42,007 & 42,007 & 27,778 \\
\hline R-squared & 0.033 & 0.034 & 0.076 \\
\hline Number of SA & 7,202 & 7,202 & 6,145 \\
\hline
\end{tabular}

Notes: Full sample. In Model (3) first and last auction in SA is excluded due to timing variables. Robust standard errors in parentheses. $* * * p<0.01, * * p<0.05{ }^{*} * p<0.1$.

\section{References}

Agarwal, A., Hosanagar, K., \& Smith, M. (2011). Location, location, location: An analysis of profitability of position in online advertising markets. Journal of Marketing Research, 48(6), 1057-1073.

Andersson, T., Andersson, C., \& Andersson, F. (2012). An empirical investigation of efficiency and price uniformity in competing auctions. Economics Letters, 116(1), 99-101.

Anwar, S., McMillan, R., \& Zheng, M. (2006). Bidding behavior in competing auctions: Evidence from eBay. European Economic Review, 50(2), 307-322.

Ashenfelter, O. (1989). How auctions works for wine and art. Journal of Economic Perspectives, 3(3), 23-36. 
Bae, J., Beigman, E., Berry, R., Honig, M., , \& Vohra, R. (2009). On the efficiency of sequential auctions for spectrum sharing. International Conference on Game Theory for Networks, 199-205.

Bajari, P., \& Hortacsu, A. (2004). Economic insights from internet auctions. Journal of Economic Literature, 42(2), 457-486.

Beggs, A., \& Graddy, K. (1997). Declining values and the afternoon effect: Evidence from art auctions. RAND Journal of Economics, 28(3), 544-565.

Deltas, G., \& Kosmopoulou, G. (2004). Catalogue vs order of sale effects in sequential auctions: Theory and evidence from a rare book sale. Economic Journal, 114(492), $28-54$.

Edelman, B., Ostrovsky, M., \& Schwarz, M. (2007). Internet advertising and the generalized second-price auction: Selling billions of dollars worth of keywords. American Economic Review, 97(1), 242-259.

Feenberg, D., Ganguli, I., Gaule, P., \& Gruber, J. (2015). It's good to be first: Order bias in reading and citing nber working papers. National Bureau of Economic Research, Working Paper No. 21141.

Février, P., L., Linnemer, \& Visser, M. (2007). Buy or wait, that is the option: The buyer's option in sequential laboratory auctions. RAND Journal of Economics, 38(1), 98-118.

Gandal, N. (1997). Sequential auctions of interdependent objects: Israeli cable television licenses. Journal of Industrial Economics, 45(3), 227-244.

Ginsburgh, V. (1998). Absentee bidders and the declining price anomaly in wine auctions. Journal of political Economy, 106(6), 1302-1319.

Grether, D., Porter, D., \& Shum, M. (2015). Cyber-shilling in automobile auctions: Evidence from a field experiment. American Economic Journal: Microeconomics, 7(3), 85-103.

Harrison, G., \& List, J. (2004). Field experiments. Journal of Economic Literature, 42(4), 1009-1055.

Hickman, B. (2010). On the pricing rule in electronic auctions. International Journal of Industrial Organization, 28(5), 423-433.

Hickman, B., Hubbard, T., \& Paarsch, H. (2011). Investigating the economic importance of pricing-rule mis-specification in empirical models of electronic auctions. Working Paper, University of Chicago, Oct. 20th.

Hong, H., Kremer, I., Kubik, J. D., Mei, J., \& Moses, M. (2015). Ordering, revenue and anchoring in art auctions. RAND Journal of Economics, 46(1), 186-216.

Jofre-Bonet, M., \& Pesendorfer, M. (2003). Estimation of a dynamic auction game. Econometrica, 71(5), 1443-1489.

Lambson, V., \& Thurston, N. (2006). Sequential auctions: Theory and evidence from the seattle fur exchange. RAND Journal of Economics, 37(1), 70-80. 
List, J. A., \& Lucking-Reiley, D. (2000). Demand reduction in multiunit auctions: Evidence from a sportscard field experiment. American Economic Review, 90(4), 961-972.

Lucking-Reiley, D. (1999). Using field experiments to test equivalence between auction formats: Magic on the internet. American Economic Review, 89(5), 10631080.

McAfee, R., \& Vincent, D. (1993). The declining price anomaly. Journal of Economic Theory, 60(1), 191-212.

Mezzetti, C. (2011). Sequential auctions with informational externalities and aversion to price risk: Decreasing and increasing price sequences. Economic Journal, 121(555), 990-1016.

Milgrom, P., \& Weber, R. (1982). A theory of auctions and competitive bidding, ii. Working Paper, Stanford University.

Raviv, Y. (2006). New evidence on price anomalies in sequential auctions: Used cars in new jersey. Journal of Business and Economic Statistics, 24(3), 301-312.

Rosato, A. (2014). Loss aversion in sequential auctions: Endogenous interdependence, informational externalities and the "afternoon effect". MPRA Paper No. 56824.

Rubinstein, A., \& Salant, Y. (2006). A model of choice from lists. Theoretical Economics, 1(1), 3-17.

Tukiainen, J. (2013). Effects of minimum bid increment in internet auctions: Evidence from a field experiment. Working Paper No. 44, Government Institute for Economic Research (VATT).

van den Berg, G., van Ours, J., \& Pradhan, M. (2001). The declining price anomaly in dutch rose auctions. American Economic Review, 91(4), 1055-1062.

Varian, H. (2007). Position auctions. International Journal of Industrial Organization, 25(6), 1163-1178.

Vickrey, W. (1961). Counterspeculation, auctions, and competitive sealed tenders. Journal of Finance, 16(1), 8-37.

von der Fehr, N. (1994). Predatory bidding in sequential auctions. Oxford Economic Papers, 46(3), 345-356.

Yoshimoto, H., \& Nakabayashi, J. (2016). Lost in transaction: Individual-level welfare loss in quickly-circulating durable goods markets with planned temporary ownership. SSRN Working Paper.

Zeithammer, R. (2006). Forward-looking bidding in online auctions. Journal of Marketing Research, 43(3), 462-476. 